This item was submitted to Loughborough's Research Repository by the author.

Items in Figshare are protected by copyright, with all rights reserved, unless otherwise indicated.

\title{
Socio-economic status and body composition outcomes in urban South
} African children

\section{PLEASE CITE THE PUBLISHED VERSION}

PUBLISHER

(c) BMJ Publishing Group Ltd

LICENCE

CC BY-NC-ND 4.0

\section{REPOSITORY RECORD}

Griffiths, Paula L., Emily K. Rousham, Shane A. Norris, John M. Pettifor, and Noel Cameron. 2019. "Socioeconomic Status and Body Composition Outcomes in Urban South African Children". figshare.

https://hdl.handle.net/2134/3386. 
This item was submitted to Loughborough's Institutional Repository by the author and is made available under the following Creative Commons Licence conditions.

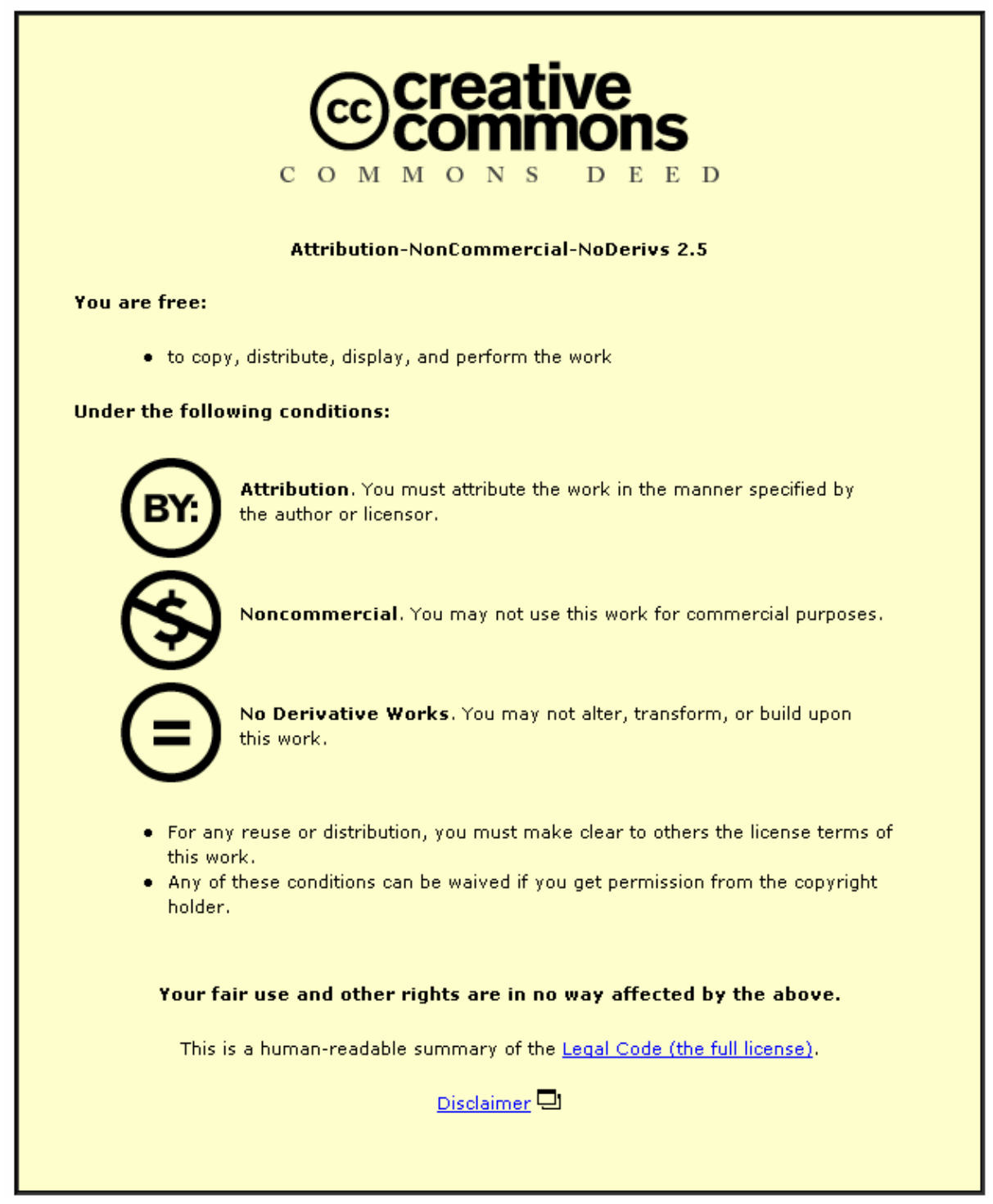

For the full text of this licence, please go to: http://creativecommons.org/licenses/by-nc-nd/2.5/ 
Socio-economic status and body composition outcomes in urban South African children

P L Griffiths ${ }^{1,2}$, E K Rousham ${ }^{1}$, S A Norris ${ }^{2}$, J M Pettifor ${ }^{2}$, N Cameron ${ }^{1,2}$

${ }^{1}$ Department of Human Sciences, Loughborough University, Loughborough, Leicestershire, LE11 3TU, UK.

${ }^{2}$ Mineral Metabolism Research Unit, Department of Paediatrics, University of the Witwatersrand Medical School, 7 York Road, Parktown 2193, South Africa

The Corresponding Author has the right to grant on behalf of all authors and does grant on behalf of all authors, an exclusive licence (or non-exclusive for government employees) on a worldwide basis to the BMJ Publishing Group Ltd and its Licensees to permit this article (if accepted) to be published in ADC and any other BMJPGL products to exploit all subsidiary rights, as set out in our licence. 


\begin{abstract}
Objective To determine which aspects of socio-economic status (SES) measured at birth and $9 / 10$ years are associated with body composition at ages $9 / 10$ years.

Design Mixed longitudinal cohort

Setting Johannesburg-Soweto South Africa

Participants A sub-sample of the Birth to Twenty $(B t 20)$ cohort $(n=281)$ with data on birthweight, height, weight, fat and lean tissue (whole body DXA), and birth and 9/10 years SES measures.

Main Outcome Measures Linear regression was used to estimate the influence of birth and ages 9/10 years SES measures on three outcomes; fat mass index (FMI) (Fat Mass $\left.(\mathrm{Kg}) / \mathrm{height}(\mathrm{m})^{4}\right)$, lean mass index $(\mathrm{LMI})$ (lean mass $\left.(\mathrm{Kg}) / \mathrm{height}(\mathrm{m})^{2}\right)$, and $\mathrm{BMI}$ at ages $9 / 10$ years controlling for sex, age, birthweight and pubertal status.

Results Compared to the lowest SES tertile, being in the highest birth SES tertile was associated with increased LMI at $9 / 10$ years $(\beta=0.43$, SE $=0.21$ for White and Black children and $\beta=0.50, S E=0.23$ for Black children only), whereas children in the high SES tertile at $9 / 10$ years had increased $\mathrm{FMI}(\beta=0.46$, SE $=0.22$ for White and Black children and $\beta=0.65, \mathrm{SE}=0.23$ for Black children only). SES at birth and $9 / 10$ years accounted for 8 and $6 \%$ of the variance in $\mathrm{FMI}$ and BMI respectively (Black children).

Conclusions These findings underline the importance of examining SES across childhood ages when assessing nutrition inequalities. Results emphasise the need to consider lean and fat mass as well as BMI when studying SES andbody composition in children.
\end{abstract}

Keywords: Obesity, underweight, socio-economic factors, fat mass, lean mass 


\section{Introduction}

Socio-economic status (SES) is known to be associated with a variety of diseases as well as adverse birth outcomes, malnutrition, stunting, and child growth ${ }^{1-9}$. Childhood SES as indicated by father's occupation, birth order, number of siblings, or occupation on entry to the workforce, has also been associated with adult mortality, ${ }^{10-13}$ cardiovascular disease ${ }^{14}$, and adult BMI ${ }^{15}$. In these studies adverse childhood social conditions are associated with higher mortality or morbidity in adulthood, even after accounting for adult SES. Some of these health associations may be mediated through differences in size at birth and childhood body composition (fat and lean mass) across SES groups. Some studies show birthweight and weight gain during infancy are positively associated with greater lean mass deposition in childhood, whereas weight gain in early ${ }^{16 ; 17}$ and late childhood ${ }^{17}$ is associated with increased adult adiposity. Yet, other studies have shown birth weight and weight gain in the first year are risk factors for obesity at 7 years. ${ }^{18}$ In general, small size at birth and low $\mathrm{BMI}$ at age 2 followed by rapid growth in childhood has been associated with increased risk of obesity, cardiovascular disease and diabetes in adulthood ${ }^{19 ; 20}$. The South African context is ideal for examining SES differences in body composition and health outcomes primarily because of the range and inequality in incomes ${ }^{21}$, and the apartheid legacy of strong associations between ethnicity, SES and health outcomes. South Africa is now a country in economic, health, and nutrition transition ${ }^{22}$. National survey data show stunting (19\%) and overweight $(17 \%)$ are similarly prevalent among children aged $1-9$ years ${ }^{23}$.

Despite the large body of research pertaining to early socio-economic environments and the association that these have with infant, child and adult health, few studies have observed SES as a dynamic variable, charting changes from birth to adolescence, particularly in a developing country context. Similarly there is a lack of research examining predictors of body composition prior to adolescence in a transitioning environment. The aim of this research is to examine which aspects of household SES measured at birth and ages 9/10 years are most important in predicting body composition outcomes at the end of childhood in the Birth to Twenty (Bt20) urban South African cohort.

\section{Methods \\ Participants}

Birth to Twenty (Bt20) is a longitudinal cohort study of 3273 singleton births that occurred between April-June 1990 to permanently resident mothers of Johannesburg-Soweto, South Africa and is described in detail elsewhere ${ }^{24 ; 25}$. At ages $9 / 10$ years, a sub-sample of children from the cohort $(n=429)$, stratified by ethnic group (Black and White) and sex, were enrolled into a longitudinal study assessing factors influencing bone health (Bone Health study). This sub-sample was composed of all the White children from the initial cohort and a random sample of Black children, all of whom had data at birth, ages 2, 4/5, and 7/8 years. Participants in the Bone Health study with data on SES at birth, birthweight, and SES, anthropometric and DXA data at $9 / 10$ years $(n=281 ; 52.3 \%$ males and $83.3 \%$ Black) were included in the current analyses.

\section{Socio-economic Status Measures}

During pregnancy or at birth, and at 9/10 years, household SES measures were caregiver assessed using a questionnaire which was based on standard measures used by the Demographic and Health Surveys (DHS) routinely administered in low income settings (see www.measuredhs.com ). In a review of 67 studies of the association between SES and child health in developing countries ${ }^{26}$, the most commonly used measures of SES were parental education, occupation, and consumer durable ownership; these were included in Bt20. The Bt20 SES questionnaire was piloted with 30 non-cohort caregivers to ensure understanding of 
concepts an optimal layout, and to test for appropriate translation of concepts.

Measures included caregiver/partner's education and occupation, number of persons in the household per sleeping room, coverage by private medical insurance, home ownership, housing type, a separate kitchen, refuse removal, the number of adults contributing financially to child support, caregiver social support, household electricity,, water/toilet facilities, and ownership of consumer durables (e.g. TV, radio, car, etc) added to at 9/10 years to reflect changing technologies available (video and microwave).

\section{Anthropometric and DXA Derived Body Composition Measures}

Weight at birth and weight and height at 9/10 years were assessed using standard techniques ${ }^{27}$. Weight was measured using a digital scale and height was assessed using a stadiometer (Holtain, UK). Two trained observers (one male and one female) recorded the anthropometric data at ages $9 / 10$ years using the same equipment. Measures of reliability were undertaken and were within expected norms. At ages 9/10 years a fan-beam densitometer (model QDR 4500A; Hologic Inc, Bedford, MA) was used to obtain dual-energy $X$-ray absorpitometry (DXA) readings of body composition The reliability of the DXA technician was assessed on a sub-sample of 20 participants using bone mineral content, bone area, and bone mineral density measures of the spine and hip. Fat mass and lean tissue mass were assessed using the adult software version 8.21 (Hologic Inc) to enable longitudinal follow-up with comparable software into adulthood and avoid changing from paediatric to adult software midway through the study. DXA scans used recommended standardized patient positioning and scan analysis ${ }^{28}$. There is no facility to assess quality control of the DXA machine in measuring lean and fat mass. However, in a previous study of UK children aged 8-12 years, Wells et al.$^{29}$ observed 'negligible mean error' in DXA (Hologic QDR 1000W) derived measures of fat free mass relative to the criterion 4compartment model

Following the methods proposed by Wells et al ${ }^{30}$, both LMI (lean tissue $(\mathrm{kg}) /$ height $(\mathrm{m})^{2}$ ) and FMI (fat tissue $(\mathrm{kg}) /$ height $(\mathrm{m})^{4}$ ) were calculated without the head component because algorithms to determine fat and lean mass for the head produce poor estimates ${ }^{28}$. Height was found to be significantly associated $(p<0.05)$ with a FMI constructed using height raised to the power of 2 . We therefore regressed log fat mass on log height to ascertain the power by which to raise height for the determination of FMI (the power was determined to be 4). For LMI height raised to the power of 2 was found to be appropriate as it did not produce a significant correlation with height. It was important to consider the power by which to raise height in constructing FMI and LMI because of the range of height values observed (range $115 \mathrm{~cm}-154 \mathrm{~cm}$ ).

\section{Pubertal Status, Sex and Ethnicity}

Pubertal development was assessed by trained same-sex observers using the Tanner scaling technique for breasts/genitalia/ pubic hair ${ }^{31}$. Caregivers reported the ethnicity of the child as recorded on the official birth notification from the 1990 South African Department of Home Affairs .

\section{Ethical Approval}

Ethical approval was granted by the ethics committees of the University of the Witwatersrand, South Africa and Loughborough University, UK. The primary caregiver gave written informed consent for their child to participate in the research at each assessment visit and the child provided written ascent.

\section{Statistical Analyses}

Linear regression analyses were used to identify birth and late childhood SES

determinants of BMI, LMI, and FMI at 9/10 years. Bivariate analyses using 
independent sample t-tests and one way ANOVA were used to test the association between each SES measure and BMI, LMI and FMI. Only significant variables with a two-tailed $P$-value $<0.05$ were retained for inclusion in the regression analysis. Because of a high correlation between some SES variables and a consequent problem of multicolinearity, an SES index was created at birth and 9/10 years that included SES measures significantly associated with BMI, LMI or FMI in the bivariate analyses. The indices were created using principal component analysis, which enabled the weights for the index of the SES measures to be determined. Scores of the first principal component were divided into tertiles to represent groups of low, middle, and high SES at birth and 9/10 years. Four linear regression models were used for each outcome, the first included only the SES indices at birth and ages 9/10 years for the entire sample. The second added the potential confounding factors of sex, age at measurement, birthweight and pubertal status for the entire sample. White children in the sample had exclusively high SES making it difficult to disentangle SES from ethnic effects on the outcomes. Therefore models three and four repeated the previous analyses using only Black children. SPSS (Chicago, IL) version 13 was used for all analyses.

\section{Results}

Descriptive data for the total sample and for each sex are presented in Table 1.

Table 1 Descriptive data for the total sample and for each sex. Body Mass Index $\left(B M I=\right.$ weight $(\mathrm{kg}) /$ height $\left.(\mathrm{m})^{2}\right)$, Fat Mass Index $(\mathrm{FMI}=$ Fat $(\mathbf{k g}) /$ height $\left.(\mathrm{m})^{4}\right)$, Lean Mass Index (LMI = Lean tissue $(\mathrm{kg}) /$ height $^{2}$ )

\begin{tabular}{|c|c|c|c|}
\hline & $\begin{array}{c}\text { Total sample } \\
\text { Mean (SD) }\end{array}$ & $\begin{array}{c}\text { Boys } \\
\text { Mean (SD) }\end{array}$ & $\begin{array}{c}\text { Girls } \\
\text { Mean (SD) }\end{array}$ \\
\hline Age (yrs) & $9.71(0.48)$ & & \\
\hline Birth weight (g) & $3187(481)$ & & \\
\hline BMI (kg.m $\left.{ }^{-1}\right)$ & $16.9(2.6)$ & $16.7(2.4)$ & $17.1(2.9)$ \\
\hline FMI ((kg. m $\left.{ }^{-1}\right)$ & $2.3(1.3)$ & $2.0(1.0)$ & $2.7(1.5)$ \\
\hline LMI $\left(\mathrm{kg} \cdot \mathrm{m}^{-1}\right)$ & $10.4(1.3)$ & $10.7(1.1)$ & $10.1(1.4)$ \\
\hline Fat Mass $(\mathbf{k g})^{1}$ & $7.81(4.46)$ & $6.71(4.00)$ & $9.02(4.65)$ \\
\hline Lean Mass $(\mathrm{kg})^{1}$ & $18.97(3.21)$ & $19.48(2.97)$ & $18.40(3.37)$ \\
\hline Tanner stage $2(\%)$ & 29.0 & 24.8 & 32.8 \\
\hline
\end{tabular}

${ }^{1}$ excluding the head

Relative SES position was dynamic between birth and ages 9/10 years. Of those born into the lowest SES tertile at birth, $51 \%$ had transitioned into a higher SES tertile by ages $9 / 10$ years (Figure 1 ). SES was also higher across all measures at birth and at $9 / 10$ years for the combined sample compared to the Black sample (Table 2). Several dimensions of birth and 9/10 year SES were associated with $9 / 10$ year body composition. Owning a range of consumer durables at birth and 9/10 years was associated with significantly higher measures of BMI and FMI, but not LMI. Additionally, those who at birth had enough money for basics, had no unemployed adult household members, and whose mother was living with a partner, and who at $9 / 10$ years were covered by medical insurance, had an employed and non single caregiver, a biological father providing financial support, and who had an indoor water tap had a higher average BMI at 9/10 years (Table 2). Children who came from households with no unemployed adult household members at birth, and where at $9 / 10$ years the caregiver was employed and not single, the biological father was providing financial support, and where the household had an inside water tap had a higher average FMI (Table 2). Children whose mothers resided with a partner at birth or at $9 / 10$ years had a significantly higher average LMI. 
Table 2 Mean (SD) BMI, FMI, and LMI in 9/10 year old Urban South African children for statistically significantly associated SES factors measured at birth and 9/10 years

\section{SES birth measures}

TV ownership

Yes

No

Car ownership

Yes

No

Enough Money for basics

Yes

No

Jobless h.hold member in last 6 months Yes

No

Mum lives with partner

Yes

No

SES 9/10 year measures

Child has medical aid

Yes

No

Video ownership

Yes

No

Microwave ownership

Yes

No

Caregiver employed

Yes

No

Caregiver single

Yes

No

Biological father provides financial support

Yes

No

Father died

Inside water tap

Yes

No

Total (n)
Mean \pm SD

BMI

N/S

78.3

(73.9)

21.7

(26.1)

37.7

(25.2)

62.3

74.8)

82.8

(80.7)

17.2

(19.3)

38.9

(45.9)

61.1

(54.1)

43.1

(32.3)

56.9

(67.7)

30.7

(19.7)

69.3

(80.3)

52.0

(42.3)

48.0

(57.7)

37.7

(27.4)

62.3

(72.6)

55.4

(50.4)

44.6

(49.6)

33.0

(39.2)

67.0

(60.8)

60.5

(55.1)

34.9

(39.8)

4.6

(5.1)

59.1

(47.8)

40.9

(52.2)

100 (281)

$\mathrm{N} / \mathrm{S}$

*

17.19

16.49

15.86

*
Mean \pm SD FMI ${ }^{2}$

$* * 4$

$2.42 \pm 1.37$

$2.02 \pm 0.81$

$2.53 \pm 1.43$

$2.21 \pm 1.16$

$17.04 \pm 2.06$

$\mathrm{N} / \mathrm{S}$

N/S

$16.19 \pm 1.84$

$16.39 \pm 1.91$

$2.03 \pm 0.91$

$17.20 \pm 2.98$

$2.53 \pm 1.43$

$17.20 \pm 3.08$

N/S

$16.54 \pm 2.20$

$10.56 \pm 1.49$

$10.19 \pm 1.11$

N/S

N/S

$17.39 \pm 3.15$

$16.65 \pm 2.32$

$17.14 \pm 3.08$

$2.49 \pm 1.41$

$16.35 \pm 1.75 \quad 2.16 \pm 0.93$

$17.36 \pm 3.10$

**

$2.64 \pm 1.65$

$16.38 \pm 2.03 \quad 2.15 \pm 0.95$

$17.23 \pm 2.99 \quad 2.05 \pm 0.86$

$N / S$

$16.45 \pm 2.03 \quad 2.56 \pm 1.50$

$16.14 \pm 1.65$

**

$10.15 \pm 1.10$

$17.27 \pm 2.95$

$2.49 \pm 1.42$

$10.51 \pm 1.37$

$2.51 \pm 1.43$

$2.11 \pm 0.97$

$1.70 \pm 0.42$

$17.16 \pm 3.01$

$2.46 \pm 1.50$

$16.50 \pm 1.92$

$2.14 \pm 0.83$

$16.89 \pm 2.63 \quad 2.33 \pm 1.27$

N/S

$\mathrm{N} / \mathrm{S}$

N/S

N/S

$0.39 \pm 1.29$ ican calculated as an index of lean mass $(\mathrm{kg}) /$ height $(\mathrm{m})^{2} \quad{ }^{4 * * *} \mathrm{p}<0.001,{ }^{* *} \mathrm{p}<0.01,{ }^{*} \mathrm{p}<0.05, \mathrm{~N} / \mathrm{S}=$ not significant 
The findings from the regression analyses are shown in Table 3 for Black children only. Any differences observed for the combined ethnic sample in regression models 1 and 2 are reported in the text only, because of the small number of White children. For Black children, SES at birth was significantly associated with BMI and FMI before controlling for confounding factors and with BMI and LMI after controlling for confounding factors (Table 3). Findings for the entire sample were slightly different, showing that SES at birth was not significantly associated with FMI, BMI or LMI before controlling for confounding factors. After controlling for confounding factors SES at birth was only significantly associated with LMI. Results from model 4 reveal that a Black child in the highest birth SES tertile could expect to have on average a BMI 1.11 units higher, and an LMI 0.50 units higher than a child in the lowest birth SES tertile..

At 9/10 years before controlling for confounding factors current SES was significantly associated with BMI and FMI (Table 3) whilst after controlling for confounding factors SES was significantly associated only with FMI. The regression findings reveal that on average a Black child in the highest SES tertile at 9/10 years could expect to have a FMI that was 0.65 units higher than a child in the lowest SES tertile (Table 3). For the Black children birth and ages 9/10 years SES measures accounted for $8 \%$ and $6 \%$ of the variance in $\mathrm{FMI}$ and $\mathrm{BMI}$ respectively. 
Table 3 Linear regression models showing the association between household socio-economic status measured at birth and ages $9 / 10$ years and Fat Mass Index (Fat (kg)/ height $\left.(\mathrm{m})^{4}\right)$, Body Mass Index (weight $\left.(\mathrm{kg}) / \mathrm{height}(\mathrm{m})^{2}\right)$, and Lean Mass Index (Lean tissue $(\mathrm{kg}) /$ height ${ }^{2}$ ) at ages $9 / 10 \mathrm{years}^{2}$ in African Black children from the Bt20 cohort (controlling for confounding factors)

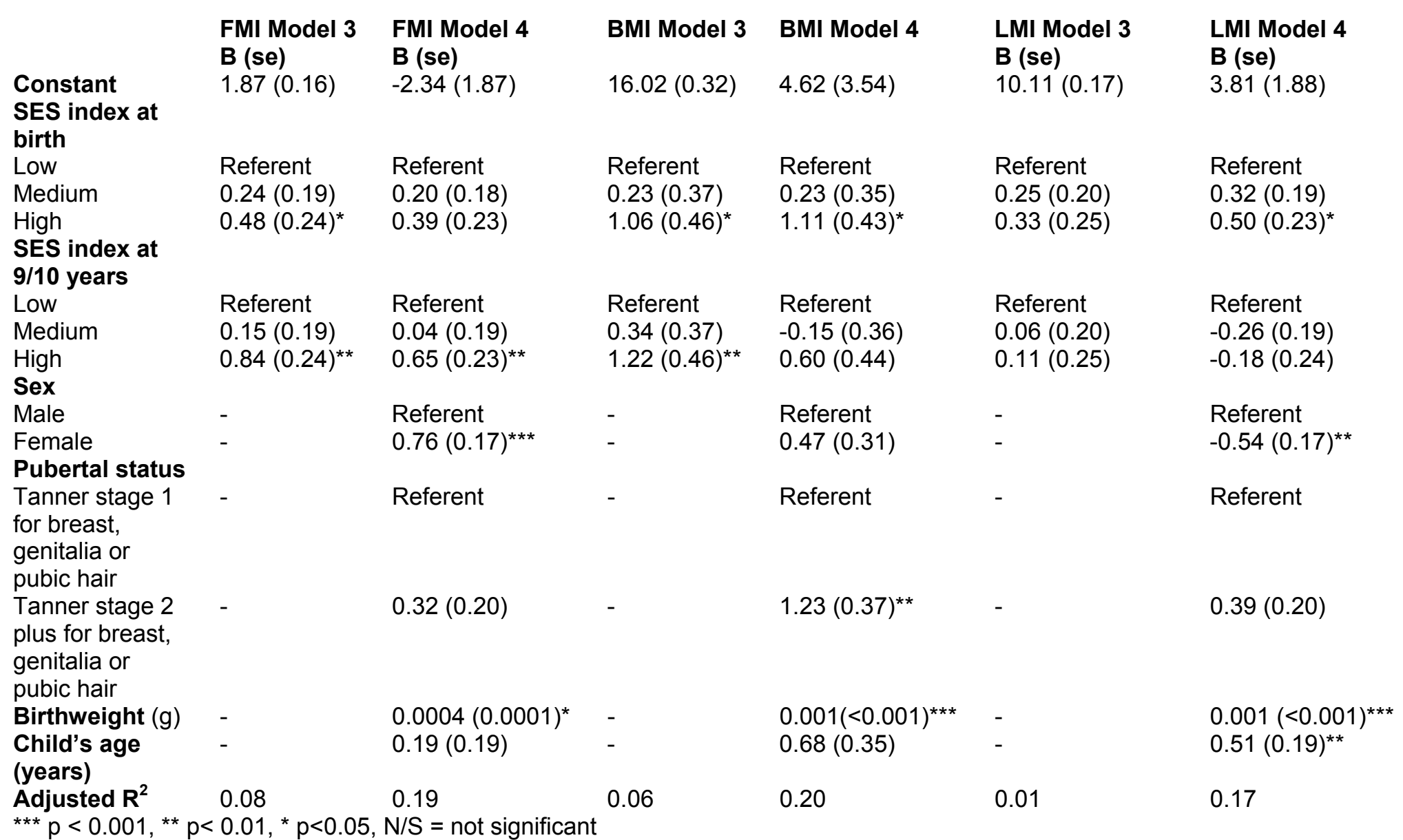


Findings from the regression analysis show that besides the SES indices, being female and a higher birthweight significantly increased FMI at 9/10 years (Table 3). For BMI, pubertal status and birthweight were significant (Table 3). For LMI, sex, birthweight, and child's age at the 9/10 year assessment were significant for the combined ethnic sample and the Black sample. Stage of pubertal development was only significantly associated with LMI for the combined sample. For the Black children adding the potential confounding factors to the SES variables in the regression models accounted for a further $11 \%$ of the variance in $\mathrm{FMI}, 14 \%$ in $\mathrm{BMI}$, and $16 \%$ in LMI.

\section{Discussion}

This study's findings suggest that early childhood SES has a stronger association with LMI, while late childhood SES has a stronger association with FMI. This difference would not have been observed if these analyses had focussed on BMI as a measure of body fatness. This finding is important because fat is the component of $\mathrm{BMI}$ that predicts later disease risk. Many studies use BMI as a proxy for body fatness because it is more easily assessed, despite its limitations of being correlated with both lean and fat mass ${ }^{32}$. The observed stronger association between SES at birth and LMI concurs with mounting evidence that lean mass is programmed by growth in utero and the first six months of life ${ }^{17 ; 33}$. The differences in body composition among these South African children at 9/10 years are likely to have health effects in later life. Children with a smaller proportion of lean mass at birth and in infancy could be susceptible to greater adipose deposition when exposed to an energy-rich environment in later childhood ${ }^{37}$. In other studies, higher BMI or fat mass in late childhood is a risk factor for adult obesity and obesity-related disorders e.g. diabetes and cardiovascular diseases ${ }^{15,}{ }^{34}$. The importance of the $9 / 10$ years SES measures for fat mass highlights the role of SES in influencing fat acquisition throughout childhood and provides evidence for the need to address inequalities beyond infancy to improve healthy body composition in children.

Despite the relatively small contribution of SES to the variance in the three outcomes, these findings are clinically important. For instance results from the regression parameter estimates from the model for Black children reveal an average BMI of 14.4 for a pre-pubertal male aged 9.75 years born of average birthweight $(3187 \mathrm{~g})$ into a low SES household and residing in a low SES household at ages 9/10 years. A similar boy born into a high SES household and residing in a high SES family at 9/10 years would be predicted to have an average BMI of 16.2. These two average boys would rank close to the $5^{\text {th }}$ and just below the $50^{\text {th }}$ percentile respectively on the CDC $2000 \mathrm{BMI}$ reference charts. Low SES in this cohort therefore presents a greater risk for wasting than obesity. However, we know that in this context of rapid nutrition transition there is an increasing risk for overweight especially among Black females (age 9 overweight prevalence in the Bt20 cohort $=10 \%$ and age $13=17 \%$ ). For children with low lean mass at the end of childhood who currently suffer the burden of under nutrition, there is also the potential future risk of a double burden from the changing energy-rich environment for greater adipose deposition in adolescence. As a modifiable risk factor SES presents opportunities for potential policy interventions. If the next generation of children born in South Africa could experience a similar SES environment from birth to late childhood to those born into the high SES tertile of the Bt20 cohort in 1990, this study's findings suggest that they would experience optimum growth into late childhood.

\section{Limitations}

The tool used to measure SES was based on those used in large scale surveys in low-middle income countries e.g. DHS. While these measures have been widely used in developing country settings, the Bt20 study did not undertake any test of 
reliability of the questionnaire used to measure SES. The choice of measures used to assess SES may influence the results that we observe because other researchers have shown that the choice of measures can influence associations between SES and child health ${ }^{35}$. Furthermore, the available measures of SES in the data set are not able to distinguish the very wealthy households. This means that the high SES group contains a diverse group of families because of South Africa's large income inequalities which result in a positive income skew.

The sub-sample used for this analysis represents a small proportion of the original $\mathrm{Bt} 20$ cohort and it is not completely socio-economically representative of the original cohort. It also contains only a small number of White children, which precludes making valid conclusions regarding differences between the two ethnic groups in the sample. The sub-sample of Black children has a significantly higher SES on some measures compared to children from the original cohort, thus under-representing the poor. Nevertheless, results show that body composition indices consistently increase with SES. It is unlikely that the direction of this association would have altered with a more representative sample, although a greater magnitude of difference could have been observed if the low SES group were more disadvantaged.

\section{Conclusion}

These findings underline the importance of considering the role of SES from birth into late childhood. Birth SES has been shown to be more strongly associated with lean mass, while SES at 9/10 years is significantly associated with fat mass in this study. Whilst this sub-sample under represents the very poorest children initially enrolled into the cohort, findings emphasise the need to consider both lean and fat mass as well as BMI in children when undertaking research investigating the effects of early life environments on body composition. 


\section{Funders}

Bt20 receives financial and logistic support from the Urbanisation and Health Programme of the South African Medical Research Council; the Anglo-American

Chairman's Fund; Child, Youth, and Family Development of the South African Human Sciences Research Council; and the University of the Witwatersrand. The Bone Health study is financially supported by the Wellcome Trust (UK). The socioeconomic analysis is funded by the Medical Research Council (UK) grant id 70363 awarded to P. Griffiths.

\section{Competing interests}

None of the authors have financial competing interests to declare.

\section{Acknowledgement}

We would like to thank $\mathrm{Dr}$ Jonathon Wells for his insightful comments on an earlier draft of this manuscript.

What is already known on this topic

Childhood social class has been associated with adult mortality among men and women as well as cardiovascular disease and BMI in adulthood.

A lack of evidence exists regarding the importance of socio-economic status at different periods of childhood and the association of these temporal measures with later risk factors for poor health.

\section{What this study adds}

Socio-economic status at birth is more important for shaping lean tissue, while socioeconomic status at 9/10 years is more significantly associated with fat tissue in this urban South African cohort of 9/10 year old children.

There is a need to consider both lean and fat mass when investigating the effects of early life environment on body composition at different stages of childhood, rather than only studying BMI because the critical ages for environmental factors to influence these different components of body mass appear to vary.

Figure Legend: Figure 1 The transitioning socio-economic profile of the African Black sample from birth to ages $9 / 10$ years 
Reference List

1. Adler NE,Ostrove JM. Socioeconomic status and health: What we know and what we don't. Annals of the New York Academy of Sciences 2002;896:3-15.

2. Barker DJP, Forsen T, Uutela A, Osmond C, Ericksson JG. Size at birth and resilience to effects of poor living conditions in adult life: longitudinal study. British Medical Journal 2001;323:1273-1276.

3. Teranishi $\mathrm{H}$, Nakagawa $\mathrm{H}$, Marmot M. Social class difference in catch up growth in a national British cohort. Archives of Disease in Childhood 2000;84:218-21.

4. Fuhrer R, Shipley MJ, Chastang JF, Schmaus A, Niedhammer I, Stansfeld SA et al. Socioeconomic position, health and possible explanations: a tale of two cohorts. American Journal of Public Health 2002;92:1290-4.

5. Yen IH,Moss NE. Unbundling education: A critical discussion of what education confers and how it lowers risk for disease and death. Annals of the New York Academy of Sciences 1999;896:350-1.

6. Sobal J,Stunkard AJ. Socioeconomic status and obesity: a review of the literature. Psychological Bulletin 1989;105:260-75.

7. Griffiths PL,Bentley ME. The nutrition transition is underway in India. Journal of Nutrition 2001;131:2692-700.

8. Popkin BM. The nutrition transition and obesity in the developing world. Journal of Nutrition 2001;131:871-3.

9. Bentley ME,Griffiths PL. The burden of anemia among women in India. European Journal of Clinical Nutrition 2003;57:52-60.

10. Davey Smith G, Hart C, Blane D, Hole DJ. Adverse socioeconomic conditions in childhood and cause specific adult mortality: prospective observational study. British Medical Journal 1998;316:1631-5.

11. Beebe-Dimmer J, Lynch JW, Turrell G, Lustgarten S, Raghunathan T, Kaplan GA. Childhood and adult socioeconomic conditions and 31-year mortality risk in women. American Journal of Epidemiology 2004;159:481-90.

12. Wamala SP, Lynch J, Kaplan GA. Women's exposure to early and later life socioeconomic disadvantage and coronary heart disease risk: the Stockholm female coronary risk study. International Journal of Epidemiology 2001;30:275-84.

13. Power C, Hypponen E, Davey Smith G. Socioeconomic position in childhood and early adult life and risk of mortality: a prospective study of mothers of the 1958 British birth cohort. American Journal of Public Health 2005;95:1396-402.

14. Blane D, Hart CL, Davey Smith G, Gillis CR, Hole DJ, Hawthorne VM. Association of cardiovascular disease risk factors with socioeconomic position during childhood and during adulthood. British Medical Journal 1996;313:1434-8. 
15. Hardy R, Wadsworth M, Kuh D. The influence of childhood weight and socioeconomic status on change in adult body mass index in a British national birth cohort. International Journal of Obesity 2000;24:725-34.

16. Sachdev HS, Fall CH, Osmond C, Dey Biswas SK, Leary SD, Reddy $\mathrm{KS}$ et al. Anthropometric indicators of body composition in young adults: relation to size at birth and serial measurements of body mass index in childhood in the New Delhi cohort. American Journal of Clinical Nutrition 2005;82:456-66.

17. Wells JCK, Hallal PC, Wright A, Singhal A, Victora CG. Fetal, infant and childhood growth: relationships with body composition in Brazillian boys aged 9 years. International Journal of Obesity 2005;29:1192-8.

18. Reilly JJ, Armstrong J, Dorosy AR, Emmet, Ness A, Rogers I et al. Early life risk factors for obesity in childhood: cohort study. British Medical Journal 2005;330:1357.

19. Rich-Edwards JW, Kleinman K, Michels KB, Stampfer MJ, Manson JE, Rexrode KM et al. Longitudinal study of birth weight and adult body mass index in predicting risk of coronary heart disease. British Medical Journal 2005;330:1115-20.

20. Barker DJP, Osmond C, Forsen TJ, Kajantie E, Eriksson JG. Trajectories of growth among children who have coronary events as adults. New England Journal of Medicine 2005;353:1802-9.

21. May J. Poverty and Inequality in South Africa: Meeting the Challenge. Cape Town: David Philip Publishers, 2000.

22. Benade AJS, Oelofse A, Faber M. Body composition in different ethnic groups in South Africa. Asia Pacific Journal of Clinical Nutrition 1996;5:226-8.

23. Steyn NP, Labadario D, Maunder E, Nel J, Lombard C. Secondary anthropometric data analysis of the national food consumption survey in South Africa: the double burden. Nutrition 2005;21:4-13.

24. Richter LM, Norris SA, de Wet T. Transition from Birth to Ten to Birth to Twenty. The South African cohort reaches 12 years of age. Journal of Paediatric and Perinatal Epidemiology 2004;18:290-301.

25. Richter LM, Norris SA, Pettifor JM, Yach D, Cameron N. Mandela's children: The 1990 Birth to Twenty study in South Africa. International Journal of Epidemiology 2007;36:s04-11.

26. Bollen K, Glanville JL, Stecklov G. Socioeconomic status and class in studies of fertility and health in developing countries. Annual Review of Sociology 2001;27:153-85.

27. Lohman TG, Roche AF and, Martorell R. Anthropometric Standardization Reference Manual. Champaign, Illinois: Human Kinetics Books. 1991.

28. Adams JE, Shaw N (eds). A Practical Guide to Bone Densitometry in Children. Camerton, Bath, UK: National Osteoporosis Society, 2004.

29. Wells JCK, Fuller NJ, Dewitt O, Fewtrell M, Elia M, Cole TJ. Fourcomponent model of body composition in children: Density and hydration of fat-free mass and comparison with simpler models. American Journal of Clinical Nutrition 1999;69:904-12.

30. Wells JCK, Cole TJ, ALSPAC Study Team. Adjustment of fat-free mass and fat mass for height in children aged $8 \mathrm{y}$. International Journal of Obesity 2002;26:947-52. 
31. Tanner JM. Growth at adolescence. Blackwell, Oxford, 1962.

32. Wells JCK. A Hattori chart analysis of body mass index in infants and children. International Journal of Obesity Related Metabolic Disorders 2000;24:325-9.

33. Singhal A, Wells JCK, Cole TJ, Fewtrell M, Lucas A. Programming of lean body mass: a link between birth weight, obesity and cardiovascular disease. American Journal of Clinical Nutrition 2003;77:726-30.

34. Guo SS,Chumlea WC. Tracking of body mass index in children in relation to overweight in adulthood. American Journal of Clinical Nutrition 1999;70S:145S-8S.

35. Houweling TAJ, Kunst AE, Machenbach JP. Measuring health inequality among children in developing countries: does the choice of indicator of economic status matter? International Journal of Equity in Health 2003;2,8. 
Figure 1 The transitioning socio-economic profile of the African Black sample from birth to ages $9 / 10$ years

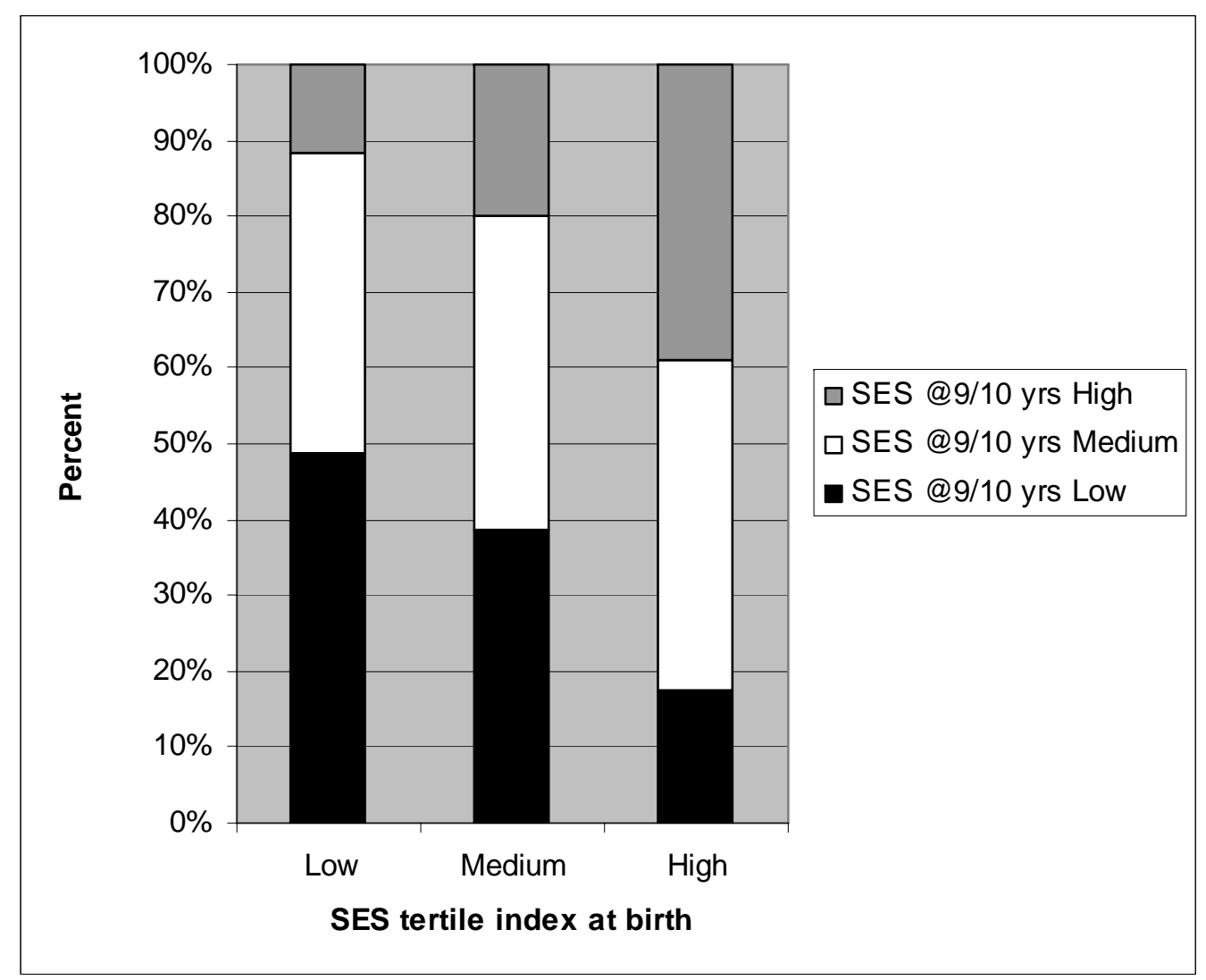

Figure 1 accompanies the paper entitled; Socio-economic status and body composition outcomes in urban South African children by P L Griffiths, E K Rousham, S A Norris, J M Pettifor, and N Cameron 